\title{
Mothers' satisfaction with delivery services and associated factors at health institutions in west Arsi, Oromia regional state, Ethiopia
}

\begin{abstract}
Background: Maternal mortality and morbidity are attributed to poor maternity quality of care. Globally, more than half a million women die annually as a result of complications of pregnancy and childbirth. So, at a time when global efforts to reduce maternal mortality have been stepped up, it is important to look at maternal satisfaction and factor affecting it.
\end{abstract}

Objective: The objective of the study was to assess the mothers' satisfaction with delivery services at health institutions and associated factors in West Arsi Zone, Oromia Region, Ethiopia, 2016.

Methods: A facility based cross-sectional survey with exit interview was conducted in West Arsi, Oromia Regional State, Ethiopia. Four hundred seventy seven (477) postpartum mothers were enrolled in the study. Data was checked, coded and entered to Epi-data and was exported to SPSS version 21 for analysis. Multivariate and binary logistic regression was applied to identify the relative effect of each explanatory variable on the outcome (satisfaction).

Results: This study finding showed that the overall satisfaction level of mothers with delivery service was $74.6 \%$. Women who had no formal education, primary education and secondary education were less satisfied than women who had diploma and above $(\mathrm{AOR}=0.851,95 \% \mathrm{CI}: 0.306,0.863, \mathrm{AOR}=0.399,95 \% \mathrm{CI}: 0.154,0.730$ and $\mathrm{AOR}=0.569,95 \% \mathrm{CI}: 0.229,0.412)$ respectively. Women who had monthly income less than $650 \mathrm{ETB}$ were three times more satisfied with delivery service than women who had monthly income more than 1900ETB (AOR=3.294,95\% CI:1.337,8.114) . Mothers who had assisted vaginal delivery were less satisfied than mothers who had caesarian section $(\mathrm{AOR}=0.31,95 \% \mathrm{CI}: 1.253,4.115)$. Mothers those their privacy measures was maintained were six times more satisfied with their delivery service at health institution than those did not maintained(AOR $=6.988,95 \%$ CI:4.047, 12.066).

Conclusion: Only $74.6 \%$ of the mothers were satisfied from the overall level of delivery service. From this study, educational status, economical status, privacy of mothers, mode of delivery and delivery were important predictors of level of satisfaction.

Keywords: Mothers' satisfaction, delivery service, health institution, west arsi zone, Ethiopia

Abbreviations: ANC, antenatal care; MMR, maternal mortality ratio; SVD, spontaneous vaginal delivery; UNFPA, united nations population fund; UNICEF, united nations children's fund; WHO, world health organization

\section{Introduction}

Maternal mortality and morbidity are attributed to poor maternity quality of care. ${ }^{1}$ globally; more than half a million women die annually as a result of complications of pregnancy and childbirth. Despite the effort and substantial amount of resources spent to reduce maternal mortality; every day, approximately 800 women die from preventable causes related to pregnancy and childbirth. Ninety-nine percent of these deaths occur in most developing countries like Ethiopia. ${ }^{2}$ Rates of maternal mortality are 19 times higher in developing countries than in developed. In the African Region, however, the MMR is still running at 540 per 100, 000 live births, which, combined with the high levels of fertility, translates into a lifetime risk of dying from maternal causes of 1 in $37 .{ }^{3}$ The current global MMR of 216 per 100, 000. The
Volume 8 Issue I - 2019

\author{
Aman Urgessa Edaso,' Girum Sebsibie \\ Teshome ${ }^{2}$ \\ 'College of Health Sciences, Madawalabu University, \\ Madawalabu, Ethiopia \\ ${ }^{2}$ College of Health Sciences, Addis Ababa University, Addis \\ Ababa, Ethiopia
}

Correspondence: Girum Sebsibie Teshome, College of Health Sciences, Addis Ababa University, Addis Ababa, Ethiopia, Email girumseb@gmail.com

Received: December 05, 2017 | Published: February 26, 2019 world's MMR fell by 44\% between 1990 and 2015, missing the target of a $75 \%$ reduction and In 2015, the African Region accounts for $64 \%$ of maternal deaths. ${ }^{3}$

Ethiopia is one among six countries which has more than $50 \%$ maternal death with 676 mothers out of 100,000 dying while giving birth. With each death there are another 20 women suffering from morbidity associated with child death. ${ }^{2}$ It is an estimated 30,000 maternal deaths take place every year. Apart from clinical causes, a number of other relevant factors such as illiteracy, lack of health care facilities, lack of health care providers and lack of transport facilities also play a major role in causing a high percentage of maternal deaths. ${ }^{4}$ In Ethiopia, like in many developing countries, the causes of maternal deaths are mainly attributed to the three delays; that is delay in seeking care, delay in reaching appropriate care and delay in receiving care. Delay in receiving care can happen due to inadequate skilled personnel in emergency obstetric care, inadequate supplies and equipment and poor quality of services. ${ }^{5} \mathrm{~A}$ woman's satisfaction with the delivery service may have immediate and long-term effects on her 
health and subsequent utilization of the services. Providing satisfying delivery care increases service utilization. ${ }^{6,7}$ Maternal satisfaction has often been defined using theoretical models of patient satisfaction. ${ }^{8}$ But there is consensus that it is a multidimensional concept, influenced by a variety of factors. ${ }^{9}$ It is therefore also defined as "positive evaluation of distinct dimensions of childbirth." 10 Evidence on mothers' 'perception of and satisfaction with the quality of maternal care help to determine other aspects of care that need strengthening in health institution delivery services to support long-term demand, generate significant changes in maternal care-seeking behavior, and identify barriers that can and should be removed. Therefore understanding women's perception of care and satisfaction with services is important in this regard, as perceived quality is a key factor affecting service utilization. ${ }^{11,12}$ Service utilization and positive maternal and neonatal outcomes can be significantly enhanced by improving quality of facility deliveries and making them more acceptable to women. ${ }^{13}$ Evaluating to what extent patients are satisfied with health services is clinically relevant, as satisfied patients are more likely to comply with treatment, take an active role in their own care, to continue using medical care services and recommend center's services to others. ${ }^{14}$ Satisfaction is not a pre-existing phenomenon waiting to be measured, rather a judgment people made reflecting their experience under specific circumstances. A simple and practical definition of satisfaction would be the degree to which desired goals have been achieved. ${ }^{15} \mathrm{~A}$ satisfied patient will recommend center's services expressing their satisfaction to four or five peoples, while a dissatisfied patient on the other hand will complain to twenty or more. ${ }^{16}$ Users, who perceive the quality of care in a health center to be good, are more likely to visit it again, thereby increasing demand for the service. ${ }^{17}$ User satisfaction is considered 'patient's judgment on the quality and goodness of care'. ${ }^{18}$ The Factors influencing the satisfaction level have also been identified which include education of the women, place of residence and their monthly income; these are non-medical factors, one of which is mode of delivery ${ }^{19-22}$ Maternal satisfaction has often been defined using theoretical models of patient satisfaction. ${ }^{23}$ This study was assessed mothers' satisfaction with delivery services at health institution and associated factors to answer the question of the prevalence of mothers' satisfaction with delivery services at health institutions and associated factors in West Arsi Zone. Study finding provided clear information about mothers 'satisfaction with delivery services and associated factor for health care providers working at study setting health institution, West Arsi Zone Health office, police makers, researchers and community on prevalence of mothers' satisfaction with delivery services and associated factors affecting the mothers satisfaction. The objective of this study was to assessed the mothers' satisfaction with delivery services at health institutions and associated factors in West Arsi Zone, Oromia Region, Ethiopia, 2016

\section{Methods and materials}

Study area and Period: This study was conducted in West Arsi Zone, Oromia Regional state, Ethiopia in Governmental Health institution. The Zone has seven woreda and one city administration, Shashemene which is allocated 275 kilometers Form Addis Ababa. Currently in west Arsi Zone, there are around seventy Eight Health centers and four Hospitals of which one Zonal Hospital and two districts and one nongovernmental hospital, which are functional during this study period for total population of 2,450,413. From this total population, 541541 are mothers in reproductive age group and among them around 85,029 of them pregnant mothers. The study period was from March 25/03/2016 to April 25/04/ 2016.
Study design: Across-sectional study design was used to assess mothers' satisfaction and associated factors affecting mothers' satisfaction with delivery services.

Source population: All women who visited, West Arsi Zone Governmental Health institutions for the delivery service were taken as a source of population, March, 2016 to April, 2016.

Study population: All pregnant mothers' who had gave birth in selected Governmental Health institutions and fulfilled the selection criteria were study population.

\section{Inclusion and Exclusion criteria}

Pregnant mothers' who had gave birth in selected Governmental Health institutions and who were discharged from the postnatal ward; during the data collection period were included to the study. Post natal mothers "who were mentally or critically ill was not include in the study subjects.

\section{Sample size determination}

Sample size was determined using the formula for single population proportion based on the following assumptions.

$$
n==(\mathrm{Z} \alpha / 2) 2 P(1-P) / \mathrm{d} 2
$$

Where: $\mathrm{n}=$ is the size of the sample, $Z \alpha / 2=$ is the standard normal value corresponding to the desired level of confidence, $d=$ error of precision, $\mathrm{P}=$ is the estimated proportion of an attribute that is present in the population which is $74.9 \%$ from Felege-Hiwot Referral Hospital, Bahir Dar city, Northwest Ethiopia. ${ }^{24}$ The calculated sample is 289 plus a non-response rate of $10 \%=318$, plus considering a design effect of $1.5(318 \times 1.5)$, a total of 477 women are required..$^{25}$

\section{Sampling procedure}

Multistage sampling technique was used to get the required study subjects. The Health centers and Hospitals were selected using simple random sampling. From these Health institutions, the Health centers and Hospitals were selected using simple random sampling by lottery method. Number of study subjects in each Hospital and Health centers were determined by proportion to population size from reviewing the first and second quarter report of 2008 Ethiopian fiscal year. ${ }^{26-30}$

\section{Method of data collection and Tools}

Data was collected using structured, exit interview questionnaire having three parts, the first containing the socio demographic characteristics of delivering mothers. The second part had Obstetric history of delivering mothers, to measure mothers' satisfaction with delivery service. The third parts containing respondents' satisfaction on health facility process, structure and distance traveled related. Delivery service satisfaction related questions were adopted and modified from the Donabedian quality assessment framework $^{8}$ and presented using a 5-scale likert scale (1-very dissatisfied, 2-dissatisfied, 3-neutral, 4-satisfied, and 5-very satisfied).The first draft of the English questionnaire was translated to Afaan Oromo language by language expert translators then back to English language to check for consistency. Seven Diploma holder Nurses were selected to collect the data; and two BSC holders Nurse were selected as a supervisors. ${ }^{31}$

\section{Data quality assurance}

Before starting the actual survey, the questionnaire was pre-tested on 24 postnatal mothers, the five percent of sample from the Hospital 
and Health centers which was not included in the study. Throughout the course of the data collection, interviewers were supervised at each site, regular meetings was held between the data collectors and the principal investigator together in which problematic issues arising from interviews which was conducted and mistakes found during editing was discussed and decisions was reached. The collected data was reviewed and checked for completeness before data entry; the incomplete data was discarded.

\section{Dependent variable and independent variables}

Mothers' satisfaction was dependent variable and Waiting time, availability of adequate human resources, medicines and supplies, Physical environment, sex, Attitude and relationship with mothers' during service were independent variable

\section{Operational definition}

Satisfied: individuals scored $75 \%$ and more from eighteen (18) items of Patient Satisfaction Questionnaire, are categorized under "satisfied" for the overall satisfaction level and for each responses of 'very satisfied' and 'satisfied' are classified as satisfied.

Unsatisfied: individuals scored below75\% from eighteen (14) items of Patient Satisfaction Questionnaire, are categorized under "unsatisfied" for the overall satisfaction level and for each responses, 'very dissatisfied', 'dissatisfied' and 'neutral' as unsatisfied.

\section{Data processing and analysis}

Data was checked, coded and entered to Epi-data and was exported to SPSS (Statistical Package for Social science) version 21 for analysis. Data entry was made by the principal investigator. During analysis, the responses of 'very satisfied' and 'satisfied' were classified as satisfied and responses of 'very dissatisfied', 'dissatisfied' and 'neutral' were classified unsatisfied. Neutral responses were classified as dissatisfied considering that they may represent a fearful way of expressing dissatisfaction. Binary logistic regression was fitted to identify factors associated with mother's satisfaction with delivery services in health institution. In descriptive statistics tables, graphs and frequency was used to present the information. Significance was obtained at Odds ratio with 95\% CI and $\mathrm{p}<0.05$.

\section{Ethical consideration}

The study was conducted after approval by the IRB (Institutional Review board) School of allied health sciences department of nursing and midwifery, AAU. Official letters was obtained from CHS, AAU to the respective officials, in turn the Zone Health Administration Office; was written a letter for study Hospitals and Health centers to get recognition and collaboration. Informed verbal consent was obtained from respondents after explaining the objective of the study. In addition, all the responses was kept confidential and anonymous by assuring that any information concerning them was never passed to any individual or institution without their agreement. A woman were kindly requested and included in the study but was told that it was their right to participate or not.

\section{Result}

\section{Socio-demographic characteristics of study population}

A total of 477 mothers who gave birth in West Arsi Zone health institutions in this study period were interviewed making a response rate of $100 \%$. Among these respondents, $76(15 \%)$ were less than 20 years, $347(72.7 \%)$ were between $20-34$ years and $54(11.3 \%)$ were above 35 years. Marital status, 446(93.5\%) were currently married, 16(3.4\%) were Single, 11(2.3\%) were divorced. Ethnicity of the respondents 305(69.9\%) were Oromo, 94(19.7\%) were Amhara, 14(2.9\%) were Gurage, $8(1.7 \%)$ were Tigria and 56(11.7\%) were other ethnicity. Two hundred forty six $(51.6 \%)$ of mothers were Muslim religion followers and followed by Orthodox Christian 122(25.6\%). Among the interviewed mothers, 96(20.1\%) had no formal education and 51 $(10.7 \%)$ had diploma and above educational Status. Occupational status of the mothers, 229(48.0\%) were house wife, $101(21.2 \%)$ were merchant, 65(13.6\%) were governmental employee and, 52(10.9\%) were farmer. Monthly income of the mothers, $216(45.3 \%)$ were no monthly income, $112(23.5 \%)$ were less than 650 ETB and $62(13.0 \%)$ were more than 1900 ETB (Table 1).

Table 1 Socio demographic characteristics of delivering mothers in West Arsi zone, Health institutions, March 25-April 25,2016 (n=477)

\begin{tabular}{|c|c|c|}
\hline Variable & Frequency & Percent (\%) \\
\hline \multicolumn{3}{|l|}{ Age } \\
\hline$<20$ years & 76 & 15 \\
\hline 20-34years & 347 & 72.7 \\
\hline $35-49$ years & 54 & 11.3 \\
\hline \multicolumn{3}{|l|}{ Marital status of the mother } \\
\hline Single & 16 & 3.4 \\
\hline Married & 446 & 93.5 \\
\hline Divorced & 11 & 2.3 \\
\hline Widowed & 4 & 0.8 \\
\hline \multicolumn{3}{|l|}{ Ethnicity } \\
\hline Oromo & 305 & 63.9 \\
\hline Amhara & 94 & 19.7 \\
\hline Tigria & 8 & 1.7 \\
\hline Gurage & 14 & 2.9 \\
\hline Others & 56 & 11.7 \\
\hline \multicolumn{3}{|l|}{ Religion } \\
\hline Orthodox & 122 & 25.6 \\
\hline Muslim & 246 & 51.6 \\
\hline Protestant & 105 & 22 \\
\hline Other & 4 & 0.8 \\
\hline \multicolumn{3}{|l|}{ Educational Status } \\
\hline No formal education & 96 & 20.1 \\
\hline Grade 1-6 & 169 & 35.4 \\
\hline Grade 7-12 & 161 & 33.8 \\
\hline Diploma and above & 51 & 10.7 \\
\hline \multicolumn{3}{|l|}{ Occupational status } \\
\hline Governmental employee & 65 & 13.6 \\
\hline Merchant & 101 & 21.2 \\
\hline Farmer & 52 & 10.9 \\
\hline House wife & 229 & 48 \\
\hline Student & 27 & 5.7 \\
\hline
\end{tabular}


Table Continued...

\begin{tabular}{lll}
\hline Variable & Frequency & Percent $(\%)$ \\
\hline Other & 3 & 0.6 \\
Economic status & & \\
No monthly in come & 216 & 45.3 \\
$<650$ & 112 & 23.5 \\
$650-1000$ & 42 & 8.8 \\
$1001-1900$ & 45 & 9.4 \\
$>1900$ & 62 & 13 \\
\hline
\end{tabular}

\section{Obstetric history of the mothers}

From the interviewed mothers, 233 (48.8\%) were multipara mothers and $152(31.9 \%)$ were prim gravid mothers. The majority, $352(73.8 \%)$ of mothers were planned for delivery services, while $125(26.2 \%)$ of mothers were referred from other health institutions for delivery service. From these mothers, 421(88.3\%) were wanted pregnancy and $56(11.7 \%)$ of the mothers were unwanted pregnancy status. Mode of delivery, 326 (68.3\%) of mothers were gave birth with spontaneous vaginal delivery, $88(18.4 \%)$ of the mothers were gave birth with Assisted vaginal delivery and 63(13.2\%) of the mothers were gave birth with caesarian section. From the mothers who gave birth in selected health institutions $423(95 \%)$ were gave birth without complication and 24(5\%) were gave birth with complication and 452 (94.8\%) of the mothers were gave birth lived fetus and 25(5.2\%) were gave birth died fetus. Prenatal care and previous facility delivery, $451(94.5 \%)$ of the mothers were had ANC follow up and 26(5.5\%) of them did not have ANC follow up, while $300(62.9 \%)$ of the mothers had previous facility delivery experience and 177(37.1\%) of them were did not have previous facility delivery experience (Table 2).

\section{Health facility and care provider related respondents' satisfaction}

Majority of the mothers $387(81.1 \%)$ were traveled less than $25 \mathrm{~km}$, $87(18.2 \%)$ were traveled $25-50 \mathrm{~km}$ and $3(0.6 \%)$ were traveled more than $50 \mathrm{~km}$ to get delivery service .Most of the mothers $327(68.6 \%)$ were used car as mode of transportation while the others 150(31.4) were traveled on their foot, Animal or human shoulder as means of transportation mode to get delivery service. Three hundred and twenty eight $(68.8 \%)$ of the mothers were satisfied with the distance they traveled to get service, but $149(31.4 \%)$ of the mothers were unsatisfied with the distance they traveled to get the delivery service. With the information on the location of the services of the hospital or health center, 404(84.7\%) the mothers were satisfied while $73(15.3 \%)$ unsatisfied with the information of the service location. Among the mothers who gave birth in selected health institution, $125(26.2 \%)$ of them were referred from other health institution .From those referred, $103(82.4 \%)$ of them were satisfied with referral link and admission at where they referred while $22(17.6 \%)$ of mothers were unsatisfied with referral link. In the selected health institutions, 327(68.6\%) of the respondents were satisfied with access of toilet while, 150(31.4\%) of the respondents were unsatisfied and 281(58.9\%) of the respondents were satisfied with cleanliness of the toilet while, 196(41.1\%) of the respondents were unsatisfied with cleanliness of the toilet.

From the mothers who gave birth in selected health institutions, $420(88.1 \%)$ were got service with exempted, while the others $57(11.9 \%)$ were paid for delivery service. Majority $(97.1 \%)$ of the mothers were satisfied with the cost of the service and 14 (2.9\%) were unsatisfied with the cost of the service. Among respondents who paid for delivery service, $22(38.6 \%)$ of them were paid less than hundred (100) ETB and 35(61.4\%) of them were paid more than hundred (100) ETB. Among the mothers who were gave birth in the selected health institutions for the study, for 216(45.3\%) of them drugs and medical supplies was ordered for them and for 261(54.7\%) were not ordered. Of those drugs and medical supplies was ordered for them, $172(79.6 \%)$ were satisfied with availability of the drugs and medical supplies at health institutions, while $44(20.4 \%)$ of the mothers were unsatisfied with unavailability of the drugs and medical supplies at health institutions which was ordered for them.

Table 2 Obstetric history of mothers who gave birth in West Arsi Zone health institutions, March 25-April 25, 2016, $(\mathrm{n}=477)$

\begin{tabular}{|c|c|c|}
\hline Variable & Frequency & Percent (\%) \\
\hline \multicolumn{3}{|l|}{ Number of parity } \\
\hline One & 152 & 31.9 \\
\hline Two-five & 233 & 48.8 \\
\hline more than five & 92 & 19.3 \\
\hline \multicolumn{3}{|l|}{ Reason for visit } \\
\hline Planned for delivery & 352 & 73.8 \\
\hline Referred for delivery & 125 & 26.2 \\
\hline \multicolumn{3}{|l|}{ Status of pregnancy } \\
\hline Wanted & 421 & 88.3 \\
\hline Unwanted & 56 & 11.7 \\
\hline \multicolumn{3}{|l|}{ Mode of delivery } \\
\hline Spontaneous vaginal delivery & 326 & 68.3 \\
\hline Assisted delivery & 88 & 18.4 \\
\hline Caesarian section & 63 & 13.2 \\
\hline \multicolumn{3}{|l|}{ Maternal out come } \\
\hline Normal & 453 & 95 \\
\hline With complication & 24 & 5 \\
\hline \multicolumn{3}{|l|}{ Fetal outcome } \\
\hline Lived & 452 & 94.8 \\
\hline Died & 25 & 5.2 \\
\hline \multicolumn{3}{|l|}{ ANC follow up } \\
\hline Yes & 451 & 94.5 \\
\hline No & 26 & 5.5 \\
\hline \multicolumn{3}{|l|}{ Previous facility delivery } \\
\hline Yes & 300 & 62.9 \\
\hline No & 177 & 37.1 \\
\hline
\end{tabular}

The waiting area for patients and relative, 429(89.9\%) of the respondents were responded as there was a waiting area, while $48(10.1 \%)$ of the respondents were responded as there was no waiting area for patents and relatives. From all respondents, 318(66.7\%) were satisfied with cleanliness and comfort of a waiting area for the patients and relatives while, $159(33.3 \%)$ of the mothers were unsatisfied with cleanliness and comfort of a waiting area for the patients and relatives. In this study, 373(78.2\%) of the mothers were satisfied with the cleanliness and comfort of examination room while, 104(21.8\%) of the mothers were unsatisfied with the cleanliness and comfort of examination room for the patients. The overall cleanliness and comfort of health facility, $422(88.5 \%)$ of the mothers were satisfied and $55(11.5 \%)$ of the mothers were unsatisfied (Table 3 ). 
Table 3 Health facility related respondents' satisfaction in West Arsi Zone, Health institutions, March 25- April 25, $2016(\mathrm{n}=477)$

\begin{tabular}{|c|c|c|}
\hline Variable & Frequency & Percent (\%) \\
\hline \multicolumn{3}{|l|}{ Distance traveled for service } \\
\hline$<25 \mathrm{~km}$ & 387 & 81.1 \\
\hline $25-50 \mathrm{~km}$ & 87 & 18.2 \\
\hline$>50 \mathrm{~km}$ & 3 & 0.6 \\
\hline \multicolumn{3}{|l|}{ Mode of transportation used } \\
\hline Car & 327 & 68.6 \\
\hline On foot, Animal or Human shoulder & 150 & 31.4 \\
\hline \multicolumn{3}{|l|}{ Satisfaction with facility distance } \\
\hline Satisfied & 328 & 68.8 \\
\hline Unsatisfied & 149 & 31.2 \\
\hline \multicolumn{3}{|l|}{ Satisfaction with information of service } \\
\hline Satisfied & 404 & 84.7 \\
\hline Unsatisfied & 73 & 15.3 \\
\hline \multicolumn{3}{|l|}{ Referred from health institution } \\
\hline Yes & 125 & 26.2 \\
\hline No & 352 & 73.8 \\
\hline \multicolumn{3}{|l|}{ Satisfaction with referral link } \\
\hline Satisfied & 103 & 82.4 \\
\hline Unsatisfied & 22 & 17.6 \\
\hline \multicolumn{3}{|l|}{ Satisfaction with toilet access } \\
\hline Satisfied & 327 & 68.6 \\
\hline Unsatisfied & 150 & 31.4 \\
\hline \multicolumn{3}{|l|}{ Satisfaction with toilet cleanliness } \\
\hline Satisfied & 281 & 58.9 \\
\hline Unsatisfied & 196 & 41.1 \\
\hline \multicolumn{3}{|l|}{ Payment status } \\
\hline Paid & 57 & 11.9 \\
\hline Free & 420 & 88.1 \\
\hline \multicolumn{3}{|l|}{ Cost paid for service } \\
\hline$<100$ & 22 & 38.6 \\
\hline$>100$ & 35 & 61.4 \\
\hline \multicolumn{3}{|l|}{ Satisfaction with cost of service } \\
\hline Satisfied & 463 & 97.1 \\
\hline Unsatisfied & 14 & 2.9 \\
\hline \multicolumn{3}{|l|}{ Ordered drugs and supplies } \\
\hline Yes & 216 & 45.3 \\
\hline No & 261 & 54.7 \\
\hline \multicolumn{3}{|c|}{ Satisfaction with availability of drugs and supplies } \\
\hline Satisfied & 172 & 79.6 \\
\hline Unsatisfied & 44 & 20.4 \\
\hline Presence of waiting area & & \\
\hline
\end{tabular}

Table Continued...

\begin{tabular}{lcc}
\hline Variable & Frequency & Percent (\%) \\
\hline Yes & 429 & 89.9 \\
No & 48 & 10.1 \\
Satisfaction with cleanliness of waiting area & \\
Satisfied & 318 & 66.7 \\
Unsatisfied & 159 & 33.3 \\
Satisfaction with cleanliness of examination room & \\
Satisfied & 373 & 78.2 \\
Unsatisfied & 104 & 21.8 \\
Satisfaction with over all cleanliness and comfort of health facility \\
Satisfied & 422 & 88.5 \\
Unsatisfied & 55 & 11.5 \\
Overall level of satisfaction of delivery service & \\
Satisfied & 410 & 74.6 \\
Unsatisfied & 67 & 25.4 \\
\hline
\end{tabular}

\section{Care provider related respondents' satisfaction}

The overall satisfaction level of mothers who were satisfied with delivery service in this study was $74.6 \%$. Of all satisfaction levels, cleanliness of toilet related satisfaction $(58.9 \%)$, cleanliness of waiting area for patients and relatives' related satisfaction (66.7\%), and access toilet of related satisfaction $(68.6 \%)$ and facility distance $(68.6 \%)$ were the first three least values (Table 3$)$. Whereas Of all satisfaction levels, cost paid related satisfaction (97.1\%), health profession related satisfaction $(91.2 \%)$, and courtesy and respects of health care provider related satisfaction $(89.5 \%)$ were the first three highest values of mothers' satisfaction with delivery services at health institutions. Among all the respondents 368(77.1\%) of mothers waiting time to see a doctor or midwife or other health care provider was less than one hour, 62(12.9\%) was 1-2 hours and $47(10 \%)$ were greater than two hours. Of these $421(88.3 \%)$ of them were satisfied with the time spent to be seen by health care providers and $56(11.7 \%)$ of them were unsatisfied.

The courtesy and respect of health care providers during care provision, 427(89.5) of them were satisfied while 50(10.5\%) of them were unsatisfied with the courts and respect of health care provider during care provision. Among these respondents, 435 (91.2\%) were satisfied with the health profession who examining them, while $42(8.8 \%)$ were unsatisfied with health profession who examining them. From the health profession examining them, 344(72.1\%) were Midwife, 71(14.9\%) were Doctor, 42(8.8\%) were health officers and $20(4.2 \%)$ were Nurses. More than half 249 (52.2\%) of the mothers who gave birth in selected health institution were attended by male sex and 228(47.8\%) were by female health care provider. Three hundred twenty seven $(68.6 \%)$ were satisfied with the sex who attended their delivery, while 150(31.4\%) were unsatisfied. From the respondents, $374(78.4 \%)$ were satisfied with the measure taken to assure their privacy, while $113(23.7 \%)$ were unsatisfied. Four hundred twenty three $(88.7 \%)$ were satisfied with information had given for them on their health problems, but 54(11.3\%) were unsatisfied. About $410(86.0 \%)$ of the mothers were satisfied with the confidentiality of health care provider and $67(14.0 \%)$ were unsatisfied. Consistency use of the service and recommending service for their family and relatives, $457(95.8 \%)$ of the respondents were reported as to use the 
service, while $20(4.2 \%)$ of the respondents were reported as do not come back again for the service. Four hundred sixty one (96.6\%) were reported as to recommending service for their family, relatives and friendlies and 16(3.4\%) were not recommending (Table 4).

Table 4 Care provider related respondents' satisfaction with delivery service at health institutions in West Arsi Zone, March 25-April 25, 2016 (n=477)

\begin{tabular}{|c|c|c|}
\hline Variables & Frequency & Percent \\
\hline \multicolumn{3}{|c|}{ Waiting time before seen by midwife or doctor } \\
\hline Less than 1 hour & 368 & 77.1 \\
\hline 1-2hours & 62 & 12.9 \\
\hline More than 2 hours & 47 & 10 \\
\hline \multicolumn{3}{|c|}{ Satisfaction with time spent before seen by midwife or doctor } \\
\hline Satisfied & 421 & 88.3 \\
\hline Unsatisfied & 56 & 11.7 \\
\hline \multicolumn{3}{|c|}{ Satisfaction with courts or respect } \\
\hline Satisfied & 427 & 89.5 \\
\hline Unsatisfied & 50 & 10.5 \\
\hline \multicolumn{3}{|c|}{ Satisfaction with profession of examiner } \\
\hline Satisfied & 435 & 91.2 \\
\hline Unsatisfied & 42 & 8.8 \\
\hline \multicolumn{3}{|c|}{ Profession of examiner } \\
\hline Doctor & 71 & 14.9 \\
\hline Midwife & 344 & 72.1 \\
\hline Nurse & 20 & 4.2 \\
\hline Health officer & 42 & 8.8 \\
\hline \multicolumn{3}{|l|}{ Sex of examiner } \\
\hline Male & 249 & 52.2 \\
\hline Female & 228 & 47.8 \\
\hline \multicolumn{3}{|c|}{ Satisfaction with sex of examiner } \\
\hline Satisfied & 327 & 68.6 \\
\hline Unsatisfied & 150 & 31.4 \\
\hline \multicolumn{3}{|l|}{ Privacy assured } \\
\hline Yes & 374 & 78.4 \\
\hline No & 103 & 21.6 \\
\hline \multicolumn{3}{|c|}{ Satisfaction with privacy } \\
\hline Satisfied & 364 & 76.3 \\
\hline Unsatisfied & 113 & 23.7 \\
\hline \multicolumn{3}{|c|}{ Satisfaction on information about health problem } \\
\hline Satisfied & 423 & 88.7 \\
\hline Unsatisfied & 54 & 11.3 \\
\hline \multicolumn{3}{|c|}{ Satisfaction with confidentiality } \\
\hline Satisfied & 410 & 86 \\
\hline Unsatisfied & 67 & 14 \\
\hline \multicolumn{3}{|c|}{ Coming back again for service } \\
\hline Yes & 457 & 95.8 \\
\hline No & 20 & 4.2 \\
\hline \multicolumn{3}{|c|}{ Recommending service for others } \\
\hline Yes & 461 & 96.6 \\
\hline No & 16 & 3.4 \\
\hline
\end{tabular}

\section{Factors influencing mother's satisfaction with delivery service at health Institution}

\section{Socio-demographic factors}

In bivariate analysis maternal age, marital status, educational status and monthly income was significantly associated with mother's satisfaction with delivery service at health institution. Mothers whose their age was less than 20 were less likely to be satisfied with delivery service than whose their age was $35-49$ at $\mathrm{p}=0.031$. (COR $=0.834,95 \%$ CI: $0.806,0.983)$.Married mothers were three times more satisfied than Widowed mothers $(\mathrm{COR}=3.130,95 \%$ CI: 1.436, 12.484). Mothers whose their educational status was 1-6 and 7-12 were less satisfied than mothers whose their educational status were diploma and above $(\mathrm{COR}=0.55,9 \% \mathrm{CI}: 0.255,0.679$ and $\mathrm{COR}=0.714,95 \%$ CI: $0.328,0.852)$ respectively.

This study revealed that women who had no monthly income less satisfied with delivery service at health institution than women who had more than 1900 ETB monthly income and women who had monthly income of less than 650ETB were two times satisfied more than women who had more than 1900 ETB monthly income $(\mathrm{COR}=0.635,95 \% \mathrm{CI}: 0.859,0.458$ and $\mathrm{COR}=2.111,95 \% \mathrm{CI}$ : $1.987,4.515)$. By applying multivariate logistic regression on socio demographic variables to control confounding effect of one variable over the other variable; Age, Marital status, Education status and economic status were adjusted. Only their educational status and their monthly income were significantly associated with satisfaction of mothers' with delivery service at health institution among sociodemographic variables at $\mathrm{p}$ value of $<0.05$. Women who had no formal education, primary education and secondary education were less satisfied than women who had diploma and above (AOR= $0.851,95 \% \mathrm{CI}: 0.306,0.863, \mathrm{AOR}=0.399,95 \% \mathrm{CI}: 0.154,0.730$ and $\mathrm{AOR}=0.569,95 \% \mathrm{CI}: 0.229,0.712$ ) respectively. Women who had monthly income less than 650ETB were three times more satisfied with delivery service than women who da monthly income of more than 1900ETB (AOR=3.294,95\% CI:1.337,8.114) (Table 5).

\section{Obstetrics history factors}

Obstetrics factors like; Number of parity, Reason for visit, status of pregnancy, Mode of delivery, Maternal outcome, ANC follow up and Previous health facility delivery experience were computed by using bivariate logistic regression analysis to identify their significance on the satisfaction of mothers satisfaction with delivery service. From these variables all have significant association with satisfaction of mothers with delivery service at health institution except number of parity and health facility delivery experience at $p$ value of $<0.05$. Mothers who had; planned for delivery, Wanted pregnancy, Normal maternal and fetal outcome and ANC follow up were two times more satisfied than mothers who had not planned delivery, unwanted pregnancy, maternal and

fetal complication and had not ANC follow up $(\mathrm{COR}=2.264,95 \% \mathrm{CI}: 1.453,3.527), \quad(\mathrm{COR}=2.297,95 \% \quad \mathrm{CI}: 1.288$ 4.096), $(\mathrm{COR}=2.288,95 \% \mathrm{CI}: 1.288,4.096$ and $\mathrm{COR} 2.905,95 \%$ CI:1.287,6.554) and (COR=2.273, 95\% CI:1.014, 5.096) respectively (Table 5). Mothers who had assisted vaginal delivery were less satisfied than mothers who gave birth through caesarian section $(\mathrm{COR}=0.404$, $95 \%$ CI: 0.356, 0.592). By applying multivariate logistic regressions on Obstetrics history variables to control confounding effect of one variable over the other variable were adjusted. Among these variables only mode of delivery has significant association with satisfaction of mothers' satisfaction with delivery service at health instructions at $p$ value of $<0.05$. Mothers who had assisted vaginal delivery were less 
satisfied than mothers who had caesarian section $(\mathrm{AOR}=0.31,95 \% \mathrm{CI}$ : $1.253,4.115$ ) (Table 5).

\section{Health facility and health care provider related factors}

Bivariate and multivariate logistic regression analysis was computed for, waiting time before seen by midwife or doctor or other health care provider, Measures taken to assure privacy, Consistency of service use and Recommending service for others. Accordingly, mothers who spent less than one hour before seen by Midwife or Doctor or Other health care provider and those their privacy was assured were six times more satisfied than mothers who spent more than two hours before seen by health care provider $(\mathrm{COR}=6.198,95 \% \mathrm{CI}: 3.279,11.714)$ and those their privacy was not assured $(\mathrm{COR}=6.363,95 \% \mathrm{CI}: 3.960,10.224)$ respectively at $\mathrm{p}$ value of $<0.05$. Mothers who responded to come back for the service were nine times more satisfied than those do not come back again for service(COR=9.934,95\%CI:3.528,27.970). Those recommending service for their family, relatives and friends were fourteen times more satisfied than those do not recommending service for others $(\mathrm{COR}=14.164,95 \% \mathrm{CI}: 3.963,50.624)$. In the multivariate logistic regression analysis; measures taken to assured privacy and recommending service for others were significantly associated with satisfaction of mothers with delivery service at health institution at $p$ value of $<0.05$. Mothers those their privacy measures was maintained were six times more satisfied with their delivery service at health institution than those did not maintained(AOR $=6.988$, 95\%CI:4.047,12.066) (Table 6).

Table 5 Socio-demographic and obstetric factors which associated with mothers' satisfaction with delivery services at health institutions in West Arsi Zone, March 25-April 25, 2016

\begin{tabular}{|c|c|c|c|c|}
\hline Variable & Satisfied & Un satisfied & COR $(95 \% \mathrm{CI})$ & $\operatorname{AOR}(95 \% C I)$ \\
\hline \multicolumn{5}{|l|}{ Age } \\
\hline$<20$ years & $49(64.5 \%)$ & $27(35.5 \%)$ & $0.834(0.806,0.983)$ & $1.105(0.488,2.504)$ \\
\hline 20-34years & $270(77.8 \%)$ & $77(22.2 \%)$ & $1.611(0.860,3.018)$ & $1.763(0.891,3.489)$ \\
\hline $35-49$ years & $37(68.5 \%)$ & $17(31.5 \%)$ & 1 & 1 \\
\hline \multicolumn{5}{|l|}{ Marital Status } \\
\hline Single & $9(56.2 \%)$ & $7(43.8 \%)$ & $1.286(0.143,11.543)$ & $1.858(0.165,20.936)$ \\
\hline Married & $338(75.8 \%)$ & $108((24.2 \%)$ & $3.130(1.436,12.484)$ & $4.055(0.459,35,850)$ \\
\hline Divorced & $7(63.6 \%)$ & $4(36.4 \%)$ & $1.750(0.173,17.686)$ & $2.194(0.178,27.042)$ \\
\hline Widowed & $2(50.0 \%)$ & $2(50.0 \%)$ & 1 & 1 \\
\hline \multicolumn{5}{|l|}{ Educational Status } \\
\hline No formal education & $78(81.3 \%)$ & $18(18.8 \%)$ & $1.057(0.447,2.499)$ & $0.851(0.306,0.863)$ \\
\hline Grade 1-6 & $117(69.2 \%)$ & $52(30.8 \%)$ & $0.55(0.255,0.679)$ & $0.399(0.154,0.730)$ \\
\hline Grade7-12 & $120(74.5 \%)$ & $41(25.5 \%)$ & $0.714(0.328,0.852)$ & $0.569(0.229,0.412)$ \\
\hline Diploma and above & $41(80.4 \%)$ & $10(19.6 \%)$ & 1 & 1 \\
\hline \multicolumn{5}{|l|}{ Economic status } \\
\hline No monthly in come & $150(69.4 \%)$ & $66(30.6 \%)$ & $0.635(0.859,0.458)$ & $1.397(0.642,3.041)$ \\
\hline$<650$ & $95(84.8 \%)$ & $17(15.2 \%)$ & $2.111(1.987,4.515)$ & $3.294(1.337,8.114)$ \\
\hline $650-1000$ & $31(73.8 \%)$ & $11(26.2 \%)$ & $1.065(0.439,2.581)$ & $1.752(0.631,4.867)$ \\
\hline $1001-1900$ & $35(77.8 \%)$ & $10(22.2 \%)$ & $1.322(0.539,3.244)$ & $1.821(0.687,4.829)$ \\
\hline$>1900$ & $45(72.6 \%)$ & $17(27.4 \%)$ & 1 & 1 \\
\hline \multicolumn{5}{|l|}{ Reason for visit } \\
\hline Planned for delivery & $278(79.0 \%)$ & $74(21.0 \%)$ & $2.264(1.453,3.527)$ & $1.674(0.988,2.836)$ \\
\hline Referred for delivery & $78(62.4 \%)$ & $47(37.6 \%)$ & 1 & 1 \\
\hline \multicolumn{5}{|l|}{ Status of pregnancy } \\
\hline Wanted & $323(76.7 \%)$ & $98(23.3 \%)$ & $2.297(1.288,4.096)$ & $1.454(0.747,2.833)$ \\
\hline Unwanted & $33(58.9 \%)$ & $23(41.1 \%)$ & 1 & 1 \\
\hline \multicolumn{5}{|l|}{ Mode of delivery } \\
\hline Spontaneous Vaginal Delivery & $260(79.8 \%)$ & $66(20.2 \%)$ & $1.832(1.010,3.323)$ & $1.018(0.496,2.091)$ \\
\hline Assisted Vaginal Delivery & $53(60.2 \%)$ & $35(39.8 \%)$ & $0.404(0.356,0.592)$ & $0.31(1.253,4.115)$ \\
\hline Caesarian Section $(\mathrm{C} / \mathrm{S})$ & $43(68.3 \%)$ & $20(31.7 \%)$ & 1 & 1 \\
\hline \multicolumn{5}{|l|}{ Maternal out come } \\
\hline Normal & $346(76.4 \%)$ & $107(23.6 \%)$ & $2.288(1.288,4.096)$ & $2.581(0.959,6.943)$ \\
\hline
\end{tabular}




\begin{tabular}{|c|c|c|c|c|}
\hline Variable & Satisfied & Un satisfied & COR $(95 \% \mathrm{CI})$ & $\operatorname{AOR}(95 \% C I)$ \\
\hline With complication & $10(41.7 \%)$ & $14(58.3 \%)$ & 1 & 1 \\
\hline \multicolumn{5}{|l|}{ Fetal outcome } \\
\hline Lived & $343(75.9 \%)$ & $109(24.1 \%)$ & $2.905(1.287,6.554)$ & $1.016(0.67,2.814)$ \\
\hline Died & $13(52.0 \%)$ & $12(48.0 \%)$ & 1 & 1 \\
\hline \multicolumn{5}{|l|}{ ANC follow up } \\
\hline Yes & $341(75.6 \%)$ & $110(24.4 \%)$ & $2.273(1.014,5.096)$ & $1.332(0.523,3.393)$ \\
\hline No & $15(57.7 \%)$ & $11(42.3 \%)$ & 1 & 1 \\
\hline
\end{tabular}

Table 6 Health facility and Health care provider related factors which associated with mothers' satisfaction with delivery services at health institution in West Arsi Zone, March 25 -April 25, 2016 ( $\mathrm{n}=477)$

\begin{tabular}{|c|c|c|c|c|}
\hline Variable & Satisfied & Un satisfied & $\operatorname{COR}(95 \% \mathrm{CI})$ & $\operatorname{AOR}(95 \% C I)$ \\
\hline \multicolumn{5}{|c|}{ Cost paid for service } \\
\hline$<100$ & $13(59.1 \%)$ & $9(40.9 \%)$ & $0.719(0.500,1.034)$ & $1.640(0.518,5.189)$ \\
\hline$>100$ & & & 1 & 1 \\
\hline \multicolumn{5}{|c|}{ Waiting time before seen by midwife or doctor } \\
\hline Less than 1 hour & $303(82.1 \%)$ & $66(17.9 \%)$ & $6.198(3.279,11.714)$ & $6.854(3.318,14.162)$ \\
\hline 1-2hours & $33(54.1 \%)$ & $28(45.9 \%)$ & $1.591(0.739,3.425)$ & $1.841(0.779,4.351)$ \\
\hline More than 2hours & $20(42.6 \%)$ & $27(57.4 \%)$ & 1 & 1 \\
\hline \multicolumn{5}{|c|}{ Profession of examiner } \\
\hline Doctor & $45(63.4 \%)$ & $26(36.6 \%)$ & $2.292(0.303,1.580)$ & $2.529(0.196,2.425)$ \\
\hline Midwife & $268(77.9 \%)$ & $76(22.1 \%)$ & $1.411(0.689,2.887)$ & $1.903(0.377,2.159)$ \\
\hline Nurse & $13(65.0 \%)$ & $7(35.0 \%)$ & $0.743(0.238,2.315)$ & $0.724(0.198,2.646)$ \\
\hline Health officer & $30(71.4 \%)$ & $12(28.6 \%)$ & 1 & 1 \\
\hline \multicolumn{5}{|l|}{ Privacy assured } \\
\hline Yes & $311(83.2 \%)$ & $63(16.8 \%)$ & $6.363(3.960,10.224)$ & $6.988(4.047,12.066)$ \\
\hline No & $45(43.7 \%)$ & $58(56.3 \%)$ & 1 & 1 \\
\hline \multicolumn{5}{|c|}{ Coming back again for service } \\
\hline Yes & $3351(76.8 \%)$ & $106(23.2 \%)$ & $9.934(3.528,27.970)$ & $1.402(0.10,9.361)$ \\
\hline No & $5(25.0 \%)$ & $15(75.0 \%)$ & 1 & 1 \\
\hline \multicolumn{5}{|c|}{ Recommending service for others } \\
\hline Yes & $353(76.6 \%)$ & $108(23.4 \%)$ & $14.164(3.963,50.624)$ & $3.151(0.364,27.253)$ \\
\hline No & $3(18.8 \%)$ & $13(81.2 \%)$ & 1 & 1 \\
\hline
\end{tabular}

\section{Discussion}

Since patient satisfaction with maternity services is an important outcome measure for the quality of care and provision of services, this study revealed mothers' satisfaction level with delivery service at health institutions. Accordingly, the overall proportion of mothers who were satisfied with delivery care in this study was $74.6 \%$ and $25.4 \%$ of the mothers were unsatisfied with overall services of health institutions at where they had their delivery. This study finding is similar with the study conducted in Felege Hiwot Referral Hospital, Bahir Dar city, Northwest Ethiopia, among women who received delivery care, where the proportion of satisfaction was $74.9 . \% 0^{32}$ and also supported by study conducted in Pakistan and Assela Hospital, among women who received delivery care, where the proportion of satisfaction were $70 \%$ and $80.7 \%$ respectively. ${ }^{18}$ But, this study finding is lower than the study conducted in Cote d'I voire, which was $92.5 \%$ of the mothers were satisfied with delivery service ${ }^{33}$ and higher than the study result found in Nairobi Kenya, Pakistan, Sri Lanka and referral hospital delivery service in Amhara Region, Ethiopia which were $56 \%, 61 \%, 48 \%$ and $61.9 \%$ of the mothers were satisfied with their delivery service respectively. ${ }^{7,18}$ This variation may be due to a real difference in quality of services provided, an increase in awareness about what mothers should have obtained in the maternity care services, expectation of mothers or the type of health facilities provided delivery service. ${ }^{34}$

The other probable reason for the difference might be, exempted from any payment for childbirth care services, increased accessibility of ambulance service for laboring mothers from their home to health institution for delivery service and an increase government concern for maternal health service in terms of qualified human power such as midwives, emergency surgery Health officers and obstetricians. According to the analytic part of this study, educational status, economic status, mode of delivery, maternal outcome, and waiting 
time before seen by midwife or doctor and measures had taken to assure privacy was statistically significant predictors of women's satisfaction childbirth care. Mothers whose their educational status was no formal education, primary education (1-6) and secondary education (7-12) were less satisfied with delivery service than whose their educational status was diploma and above $(\mathrm{AOR}=0.851,95 \% \mathrm{CI}$ : $0.306,0.863),(\mathrm{AOR}=0.399,95 \% \mathrm{CI}: 0.154,0.730)$ and $(\mathrm{AOR}=0.569$, $95 \%$ CI: $0.229,0.412)$ respectively. The study conducted in Pakistan supported this result. ${ }^{4}$ This is might be due to greater experience and maturity as their educational status is increased. The other probable reason for this result is might be expectation that health care providers have for educated and not educated and educated mothers might be not have difficult to communicate her problems with health care providers during care provision. But, the study conducted in Ghana, Nigeria, and Zambia contradicted with this result, which showed mothers' educational levels negatively affected their satisfaction with maternal care ${ }^{34}$ and the study conducted in Assela Hospital found that mothers whose their educational status was secondary school level (712) were 2.42 times more satisfied with delivery service than diploma and above $(\mathrm{AOR}=2.42,95 \% \mathrm{CI}: 1.17,5.00)$.

Women who had monthly income was less than 650 ETB were 3.294 times more satisfied with their delivery service at health institution than women who had monthly income of more than 1900 ETB monthly income (AOR $=3.294,95 \%$ CI: 1.337, 8.114) (Table 5). This study finding is supported by the study conducted in Assela Hospital which showed mothers 'who had monthly income of less than 500ETB were 2.40 times more satisfied with their delivery service than mothers'those their monthly income was more than 1000ETB (AOR $=2.40,95 \% \mathrm{CI}: 1.25,4.78 .{ }^{29}$ This might be as economic status of mothers increased mothers expectation on delivery service increased with their monthly income increment. Mothers who had assisted vaginal delivery were less satisfied than mothers who had caesarian section $(\mathrm{AOR}=0.31,95 \% \mathrm{CI}: 1.253,4.115)$. This study is supported by the Study conducted in Amhara, Ethiopia found that mothers, who gave birth by SVD (spontaneous Vaginal Delivery) (142 (34\%) more satisfied than assisted delivery $70(16.8 \%))^{32}$

From this study, mothers' who had seen by doctors or midwife or other health care provider at less than one hour were 6.854 times more satisfied with their delivery service than mothers' who had seen at more than two hours (AOR=6.854,95\% CI:3.318,14.162). This study result finding is supported by study conducted in Assela Hospital and Amhara region Hospital which showed that mothers' seen by health care provider less than one hour were 26.7 times more satisfied (AOR:26.7,95\% CI:5.56,12.81)and 2.9 times more satisfied ( $\mathrm{AOR}=2.9,95 \% \mathrm{CI}: 1.14,7.58)$ than mothers 'those visited at more than two hours respectively. ${ }^{29,32}$ This study finding suggest that mothers those their privacy measures was maintained were 6.988 times more satisfied with their delivery service at health institution than those did not maintained (AOR=6.988, 95\%CI: 4.047, 12,066) .This finding is supported by study conducted in Bangladesh and India which showed maintenance of privacy via a separate room or screen for examination or delivery was a significant factors affecting of satisfaction with maternal health services in. ${ }^{25,31}$ Finally this study may have limitation on the study design and study approach because satisfaction can be assessed better with qualitative approach.

\section{Conclusions and recommendations}

The overall satisfaction of hospital delivery services in this study is found to be suboptimal. The study strongly suggests that more could be done to assure that services provided are more patient centered. This study also revealed several constraints in the provision of delivery care services which can be implied as areas of possible improvement; including educational status, economic status, mode of delivery, waiting time before seen by health care provider and maintaining the privacy of the mothers. Health institution should work on cleanliness of waiting area, compound, examination room and cleanliness and access of toilet. Caregivers need to fully understand the expectations that patient have for their care, and provide care that is consistent with those expectations. The care givers of the facility should avoid staying longer waiting time to see the delivering mothers, breeching confidentiality and privacy of mothers. Future studies should consider gathering more data from a more diverse sample to address the generalizability issue.

\section{Acknowledgments}

My thanks also go to Addis Ababa University College of health sciences school of Allied Health Sciences Department of Nursing and Midwifery for all the efforts made to provide me with the necessary knowledge and skill to conduct the study. My very great gratitude goes to my wife Dero Gudeto and my child Neima Aman for their unlimited encouragement, moral, material and financial support throughout the course and the research work.

\section{Conflicts of interest}

The author declares there are no conflicts of interest.

\section{References}

1. Hulton LA, Mathews Z, Stone RW. A framework for evaluation of quality of care in maternity services. UK: University of South Hampton; 2000. $40 \mathrm{p}$.

2. WHO. Maternal mortality. Fact sheet NO 348. 2014. 4 p.

3. WHO. Health in2015 from MDGs to SMDGs. Geneva, Switzerland, 2015. 204 p.

4. Choudhry TM. Maternal mortality and quality of maternity care: Implications for Pakistan. Sweden: Master's Thesis, Karolinska Institutet; 2005. $11 \mathrm{p}$.

5. Ministry of Finance and Economic Development. MDGs Report: Trends and Prospects for Meeting MDGs by 2015. Addis Ababa, Ethiopia, 2010. 128 p.

6. Coeytaux F, Bingham D, Langer A. Reducing maternal mortality: a global imperative. Contraception. 2011;83(2):95-98.

7. Bazant ES, Koenig MA. Women's satisfaction with delivery care in Nairobi's informal settlements. International Journal for Quality in Health Care .2009;21(2):79-86.

8. Donabedian A. An Introduction to Quality Assurance in Health Care. USA: Oxford University Press; 2002. 240 p.

9. Christiaens W, Bracke P. Assessment of social psychological determinants of satisfaction with childbirth in a cross-national perspective. BMC Pregnancy Childbirth. 200;7:26.

10. Linder Pelz S. Toward a theory of patient satisfaction. Soc Sci Med. 1981;16(5):577-582.

11. Andaleeb SS. Service quality perceptions and patient satisfaction: a study of hospitals in a developing country. Soc Sci Med. 2001;52(9):1359-1370

12. WHO, UNICEF, UNFPA, WORLD BANK. Maternal mortality 
Estimates Developed by WHO, UNICEF, UNFPA and the World Bank. 2011.12 p.

13. Mpembeni RNM, Killewo JZ, Leshabari MT, et al. Use pattern of maternal health services and determinants of skilled care during delivery in Southern Tanzania: implications for achievement of MDG5 targets. BMC Pregnancy Childbirth. 2007;7:29.

14. Pascoe GC. Patient satisfaction in primary health care: a literature review and analysis. Eval Prog Plan.1983;6(3-4):185-210.

15. The Health Boards Executive. Measurement of patient satisfaction guideline 2. Ireland: Health Strategy Implementation Project; 2003. 37

16. Ghobashi M, Khandekar R. Satisfaction among expectant mothers with antenatal care services in the musandam region of Oman. Sultan Qaboos Univ Med J. 2008;8(3):325-332.

17. Dettrick Z, Firth S, Soto EJ. Do strategies to improve quality of maternal and child health care in lower and middle income countries lead to improved outcomes? A review of the evidence. Plos One. 2013;8:e83070.

18. Ashraf M, Ashraf F, Rahman A, et al. Assessing women's satisfaction lelel with maternity services: Evidence from Pakistan. International journal of collaborative Research on Internal Medicine and public Health. 2012;4(11):1-11.

19. Rudman A, EL Khouri B, Waldenstrom U. Women's satisfaction with intrapartum care-a pattern approach. J Adv Nursing. 2007;59(5):474487.

20. Proctor S. What determines quality in maternity care? Comparing perceptions of childbearing women and midwives. Birth. 1998;25(2):85-93.

21. Pakgohar M, Jamshidi Ovanki F, Mehran A, et al. Satisfaction of infants' parents about health care. Hayat. 2004;10(1):23-29.

22. Thomason J, Edwards K. Using indicators to assess quality of hospital services in Papua New Guinea. Int $J$ Health Plann Manage. 1991;6(4):309-311.

23. Changole J, Bandawe C, Makanani B, et al. Patients' satisfaction with reproductive health services at Gogo Chatinkha Maternity Unit,
Queen Elizabeth Central Hospital, Blantyre, Malawi. Malawi Med J. 2010;22(1):5-9.

24. Assefa F, Mosse A. Assessment of Clients? Satisfaction with health service deliveries at Jimma University specialized hospital. Ethiopian Journal of Health Sciences. 2011;21(2):101-110.

25. Dzomeku MV. Maternal satisfaction with care during labor: a case study of the Mampong-Ashanti district hospital maternity unit in Ghana. International Journal of Nursing and Midwifery. 2011;3(3):30-34.

26. Hasan A. Patient satisfaction with MCH services among mothers attending the MCH training institute in Dhaka, Bangladesh. Master's thesis L Mahidol University; 2007. 94 p.

27. Heidari RMD, Borna SMD, Haghollahi F, et al. Satisfaction with the prenatal clinics in Zanjan, Iran. J Family Reprod Health. 2008;2(1):4148.

28. Singl H, Haqq ED, Mustapha N. Patient's perception and satisfaction with health care facilities in Trinidad and Tobago. Bull WHO. 1999;77(4):356-358.

29. Amdemichael R, Tafa M , Fekadu H. Maternal Satisfaction with the Delivery Services in Assela Hospital, Arsi Zone, Oromia Region. Gynecol Obstet (Sunnyvale). 2014;4(1):12.

30. Delvaux TG-KV, Bosso P, Collin S, et al. Quality of normal delivery care in Côte d'Ivoire. Rev Afr Santé Reprod. 2007;11(1):22-32.

31. Mosallam M, Rizk DEE, Thomas L, et al. Women's attitudes towards psychosocial support in labour in United Arab Emirates. Arch Gynecol Obstet. 2004;269(3):181-187.

32. Mekonnen M E, Yalew WA, Anteneh ZA. Women's satisfaction with childbirth care in Felege Hiwot Referral Hospital, Bahir Dar city, Northwest Ethiopia, 2014. BMC Res Notes. 2015;8:528.

33. Delvaux TG-KV, Bosso P, Collin S, et al. Quality of normal delivery care in Côted'Ivoire. Rev Afr Santé Reprod. 2007;11(1):22-32.

34. Aldana JM, Piechulek H, Al-Sabir A. Client satisfaction and quality of health care in rural Bangladesh. Bull World Health Organ. 2001;79(6):512-517. 